\title{
The Journalistic Categories and Their Structure in the Pages of "Llaiko Vima" Newspaper (1945-2012)
}

\author{
M.Sc. Olieta Polo \\ "Eqrem Çabej” University of Gjirokaster, Faculty of Education and Social Sciences, Department of Greek Language, \\ Literature and Greek Civilisation, Gjirokaster, Albania \\ Email:poliouolga@yahoo.gr
}

\section{Doi:10.5901/mjss.2015.v6n2s1p238}

\section{Abstract}

The aim and the objectives of the newspaper can be divided in four schematic groups: a) ideological, b) political, c) cultural, educational and scientific and d) objectives connected with the process of economic production. By the aim and objectives of the newspaper depended even the orientation for the strcture of journalistic material, their spreading in pages, the graphic details and even the very elemnts of paging. There is a lot of information about everyday life of the Ethnic Greek Minority, about their weddings, celebrations, religion, school activities, permanent rubrics, scientific and social life articles. A special rubric was dedicated to the writers and poets of this minority. The newspaper has discipline and ideological uniformity and this one of its main characteristics. The editors of the selection rubric in general want the autonomy of their newspaper that has such a great impact to the people of Greek Minority. The newspare is varied and polimorphic because it treats different spheres like romantic-philosophical chronicles, lyrical, erotic etc.

Keywords: the journalistic categories; the structure of journalistic categories; social life articles, special rubrics, actuality rubrics.

\section{Introduction}

The newspaper all the time compiled manuals with the aim to improve the ideological base of correspodents.Often it published advices for the correspodents to consider them in their work. E.g. in the pages of the newspaper on 03.08. 1945 the editorial office presented for its co-operators, the following directions:

a) "not to be occupied with general topics.

b) to prefer themes of people's lives and their problems.

c) the space of the newspaper is limited so to avoid the big correspodences from $1 / 3$ till in the $3 / 4$ of the page by an application page.

d) the correspodence to have a rich content and to be more correct by the linguistic point of view."

The correspodents that followed loyally the directions of the editorial office took prizes. In the cases when the editorial office thought that the correspodents had negative thoughts, fired them. The old correspodents had even the leading role for the youngest.

The format of the newspaper and the selection of the material had to satisfy some rules that were decided by the centre, by the head, meaning by the party. The newspaper was obliged to publish in every page articles that showed workers' contribution at work and as well as their efforts in marxist-leninist education, and even the job that the communist did in work places, so as to rich this pupose. The pages of the newspaper had to be attractive, beautiful, bright and alive. At the same time in the economic issues the newspaper had to offer the possibility that the readers to open their horizons with their homologues of the socialist camp. The published material would be classified in five groups:

In articles, reportages and correspodences that occasionally took the place of the editorial (leading article).

1. In correspodences that were included in special rubrics (costantly, occasional and extraordinary)

2. In independent articles(comments).

3. In materials of philological nature (poems, sketches, stories, folk, novels' and stories fragments, historical writings etc).

The articles that placed the editorial are divided in six groups:

a) texts(speeches) of the main leaders, and decisions of the high forums of the Party in Tirana usually signed by E. Hoxha.

\footnotetext{
${ }^{1}$ Newspaper "Llaiko Vima”: 03.08.1945.
} 
b) decisions of the local organs of the party and Govern, signed by the local leader.

c) historical decision of PPSH (Labour Party of Albania).

d) political texts(articles) of the newspaper's editorial office (editorials).

e) Correspodences and reportages from the real life of Ethnic Greek Mnority.

f) (rarely) important philological materials, that used to make repercussion to the reality.

Specific rubrics, that were presented in the newspaper's pages are classified in three categories:

a) permanent rubrics

b) occasionally and

c) extraordinary.

The occasinally rubrics can be classified according to their reference:

a) activities in agriculture,

b) activities in schools,

c) in schhol's life and

d) with foreign news.

There are even rubrics that refer all the categories of social and cultural life. The newspaper gave them a special place, according to times, extraordinary stories of the party's life, in rubrics as: "Party's Life", "Party's Congresses", "the elections of the Party's organizations", etc.

The objectives in the cultural field and in the social-cultural education, were the strengthen of the feeling of love for the socialist fatherland, cooperation, brotherhood and the religious, provincial cohabitation, the sacrification for the protection of Fatherland etc. There were ordered the artists to search their spiritual inspiration always at people, in the different victories of the new to the old and in the middle of the ones that would fight for the realization of big public work etc.

The artists of every field, the workers of the massive culture and the teachers too were considered as 'the socialist builders", capable to create the model and the image of the communist society. To reach this objective, they themselves had to be politically educated through learning Marx', Lenin and Stalin lessons and to be known by the patriotic view, social, party activities.

The first page of the newspaper, was unchanged all along its publication. The graphic changes, that might have happened are small e.g. a few times the title is presented in another colour, sometimes it is presented the symbol of socialism build and the title "Llaiko Vima' proves the change of letters from big into small and the opposite(only at the word "Llaiko").

The newspaper passes through a careful publication, that it's distinguished by the illustrations and the graphic styles as the technic allows and the time aesthetic; its pages printed well, one rubric or two rubrics in each page,but the form of each page changes according to the typographic characteristics of press. Illustrations are more careful and include except typographic decorations even landscapes, different pictures, buildings of the Ethnic Greek minority and other places with historical and archeological values, photo-portraits, work-projects maps etc.

In the main place(usually the frontal one) is the article which normally continues even in the second page. There are also special small studies and articles with different topics, historic, folk, archeological, literary,stories, proze, texts, poems, the rubric "The books' critics", announces of new publications as well the rubric "Correspodence". In the last page there are spaces for the outside actuality, subtitles as "Outside news", "Events from the world", "Comments" etc.

After 1990s in the last pages of the newspaper predominate more the advertisements.

The first page of each newspaper is very important, it is its "face", its "heart". So its titles and the key-words placed in visible places, maybe even styled, thicken its message according to each situation that represents the editorial's name, or orderers according to the occasion: ideological or commercial.

In the first page of the newspaper "Llaiko Vima", as in all the Albanian newspapers of the time, prevails the leading article, at the top and centre of the page, in the role of the editorial or main article which suggests one or two important topics, main actualities of the week. Usually these actualities are totaly of political and party character, placed in the local format, locative, regional in the way of directives from which working forces had to get inspired for the realization of economical and social works. Sometimes except from the main article and the editorial, in the first page there was a little space for an important chronicle or rarely for a poetry that illustrated enthusiastic revolutionary moments.

The most frequent and present journalistic categories in every number are, almost published are the Editorial, Leading Article and Reportage. Editorials are formed in years mainly by the editors and the group of main editors. They reflect clearly the ideological, political and central orientations, but in many cases even the directions of political leaders and local leaders, mainly at the end of the Party's pleniums and conferences or the Youth, Women, Pioneer organizations etc.Editorials were opened social,organizative advices and military calls to act in a collective way, leaded in a specific 
direction in foundations of which always consisted the ideological spread of Marx, Engels, Lenin and Stalin and the best assimilation of these lessons mainly by the party's leaders of the Ethnic Greek Minority and different organizations, that operated in this space. In the role of the leading article, always on the first page, most of the times were published the speeches of of the Excutive Leaders of the Party and state, E.Hoxha read in the Politic Byroe, in enterprises, institutions,schools etc. In other cases as leading editorials were used the writings of E.Hoxha at the central newspapers and mainly "Party's Road" magazine. The practical and useful aim of these leading articles were the execution of Party's directions in the main fields of as were: the education development, the socialism, the political education of people, the cultural development of different stratas in the Ethnic Greek Minority, the strengthen of Party-People unity etc. The practic and useful purpose of these leading articles was the excution of the Party's decisions in the main fields of socialism build as were many times, these party directives projected in a funny way, situations without meaning and the waste of human energies in an unjustified way. Reportages were presented as journalistic texts in which coexisted the directives and the human fact. The reportages' authors searched in the EGM spaces and were bringing in the newspaper realities and social, educational, ideological and cultural facts that contented the directive, seeing it realised in practice. It was given a great care that every moment was prominent the idea of the superiority of the new world in connection with the old world and the old capitalist period. This superiority was based in two basic elements, in the faith of a law or the historic determination that the socialism directed for the creation of the new man. The projection of this man, as well the elements that formed his sterotype were dominant topics in the "Llaiko Vima" newspaper, which tried to convince its readers that the communists were part of advanced category of people, in the kind of "the new man".

One of the most journalistic kinds results to be the chronicle. The chronicle ${ }^{2}$ of "Llaiko Vima" newspaper is the micrography of the ideological world of the newspaper given through the authors' texts that produced in its rubrics. The chrinicle is a category of journalistic writing,various and polymorphic. The variety is a general feature of it with a descriptive form, narrative or essay. Chronicles' thematology included social aspects, romantic and philosophical, theological, political,revolutionare and folk movements, linguistics, necrology, ancient history, national conciousness and new technology. One of the most frequent journalistic kinds results to be the chronicle.

The newspaper "Llaiko Vima" is varied and polymorphic, because it treats different topics and different spheres. The romantic-philosophical chronicles and lyrical-erotic are given according to the romantic view. These texts, in which in everyday life fight the emotions and excitement, are characterized not literary and are exercises of style. They present realities with a dense lexicon or concentrated and more exactness in formulation. As such are the most special human moments of the newspaper.

The chronist of this newspaper usually(the one that writes chronicles) goes on with the excuse of a visit or a journey in the world of the past where he sees old elements which should oppose the present, considering it undeserving and unworthy. Most of the other topics of the chronicles are copies or printings of the general social-political reality of the after war period, according to the immitation of the journalistic social-realistic typology, that was executed in all the organs of the albanian written press of the time. So in this context they are texts of ideological propaganda, meaning that they have no connection with literature and the aim of its union with journalism and jornalistic stylistic can be characterised as a journalistic "frozen", ideological and dictated style, a little satirical, under the contemporary spectrum and deeply political.The journalistic reality of "Llaiko Vima" newspaper is a simple journalism with partial emphasised dimensions, a service of the specific political aims, a didactic journalism, (many times) with a style that has no connection with the one that requires the specific kind of writing(the chronicle). The chronicle with political topic at "Llaiko Vima" newspaper includes the main political orientation, because it can't be justified the show and its resistance, from the year 1945 till at the end of the years 1980.

The first chronicle in "Llaiko Vima" newspaper was shown with the title "To save brothers" 3 signed with the pseudonym "J.K". Some of the first chronicles in "Llaiko Vima" newspaper are: "Gets out backwards"4 signed with the pseudonym "J.K", "Are coming"5 signed with the pseudonym "L", "With uncle Thimio"6 signed with pseudonym "J", "Insatiate"7 unsubjugated, "Democracy"8 unsigned, "The Patriot"9 signed with pseudonym "Dhrinioti", "Durres-Elbasan"10

\footnotetext{
2 For the chronicle look in the word Chronicle, in the chapter 24, pg.727 in "The Great Greek Encyclopedia".

${ }^{3}$ Newspaper "Llaiko Vima": 20.07.1945.

${ }^{4}$ Newspaper "Llaiko Vima": 27.07.1945.

${ }^{5}$ Newspaper "Llaiko Vima": 10.07.1945.

${ }^{6}$ Newspaper "Llaiko Vima": 27.08.1945.

${ }^{7}$ Newspaper "Llaiko Vima": 17.09.1945.

8 Newspaper "Llaiko Vima": 01.10.1945.

${ }^{9}$ Newspaper "Llaiko Vima": 20.09.1946.

10 Newspaper "Llaiko Vima": 18.01.1947.
} 
unsigned, "the Timetable... of Vasili"11 of Jani Thano and Pano Cuka, "Parrots"12 of Pano Cuka, "The Nerons of Wall Street"13 of Pavlo Shuti, "Uncle Loli is in Love"14 of P.Kastriti and A.Vrahuli, "The dream of a summer night"15 of Kosta Raka, "The meeting that got seasick"16 of Sokol Gjoka etc.

The other pages that follow with the rubrics of the newspaper and according to their content are distinguished short news rubrics and long ones of the country, educational events, healthy and philological, inside and outside news, laic philosophy, etc, which determine a specific number of the registration of the basic material, organised according to a structure that is almost kept from one number to the other.

The rubrics of everyday events from the country with the titles "Life and youth move", "Life and Movement"etc, prove that is about those rubrics that show short and different by the everyday life of the country. These rubrics give episodes by everyday events e.g. accidents,crimes, stealings, last week's weather(with its impact to the economic activity and more rarely in the social activity), religious celebrations and fair's description, school's life viewpoints, news with social themes, statistic elements for public service of the city.

Of special inerest are the news with facts for the State Administrate and its institutions, of the commercial movement, facts of farm life and different jobs according to season, greetings, wishes for the reader, but even advertisements or announcements, declarations, information given in a special way for each of them. Of interest is the special style in the presentation of everyday themes.

The existence of a special rubric with the title "In the build road" or "In the development road", in which continously are given lots of problems and will characterise it according to its impact, as one of the best rubrics, of special inerest.

All the news with "social" problems of the newspaper, if they are noticed and studied carefully, will give clear ideas for the support of the Albanian society of the time and taken and published together, make together even an "archive" of society.

The announcements, information, the notices of "family-social" from the newspapers show the lively course of everyday life, that has its "stations" with wedding declarations, births, bapstisms, developments, progress, social solidarity, naturally including diseases and deaths.

As for the rubrics of the main local news are those that aim and cover journalistically the economic and social development of the Ethnic Greek Minority. The local news rubrics describe the voting procedures and elections in villages or different enterprises. This was characteristic of social and political reality in the first years of the communist system. Many rubrics treat such issues connected with different ecclesiastic proceses, echoes from annual of working groups, moments of village's life, problems of the hygiene and the environment cleaning of the country, descriptions from the celebrations of national celebrations etc.

Whereas the news rubrics "curious or strange" or "extraordinary" seem to have had as a purpose to inform the all the public, that like to read such news, for intelectual and mental interest but even for entertainment and encyclopedic curiosity. There are too many readers of this category that prefer news, readings or themes that aren't identified with everuday reality in front of them, but with realities from science-fiction world.

In the newspaper there are many articles and studies with phylosophical content and moral-didactic. Through studies, often there are advices, behavioral examples, values examples, the distinction between good and evil, that flow and can be taken from the tone and position of the newspaper.

As for the rubrics of bibliography, literature or the books advertised through critic-literature writings, they are one of the clearest testimonies of the educational mission and phylologic character of the newspaper. The information of the reader for the new publications, that was always the main concern of the publication of philological magazines passes even at the newsaper "Llaiko Vima" with a lot of references and different titles. The books and magazines' presentation is the frequent journalistic kind and usual, with short writings for the author, genre, content, its social literature values atc. Much nicer is this rubric when it refers to a publication or publications of the poets and writers of the Ethnic Greek Minority. In this case they are presented with decorated style and tone and emotional, whereas the criticism about the content elements of the book are limited.

Thematic scientific unity of "Llaiko Vima" newspaper includes:

a) studies and articles in different fields of science, especially physics, of new technology, of botanic etc.

\footnotetext{
${ }^{11}$ Newspaper "Llaiko Vima”: 22.09.1955.

12 Newspaper "Llaiko Vima": 10.11.1955.

${ }^{13}$ Newspaper "Llaiko Vima": 08.01.1956.

${ }^{14}$ Newspaper "Llaiko Vima": 06.12.1956.

${ }^{15}$ Newspaper "Llaiko Vima": 07.08.1983.

${ }^{16}$ Newspaper "Llaiko Vima”: 31.12.1989.
} 
b) analysis of theoritical issues religion relationships, science and metaphysic, war, music etc.

c) interesting thoughts for technology and culture.

d) medicine, is the science that is presented (with articles and simple advices) more often in the newspaer, and the same rubrics form a manifestation of social services of newspaer to its reader.

e) in the newspaper we find even the rubric for announcements from the juridical activities.

As for the satire we identify it in the rubric with title "Qendrismata"("Stingings) Initially the satire was seen connected with same kinds with which was confused such as humour, irony and sarcasm and for this reason it is less developed, because the publishers or the editors believe that the style of satiric word "is not allowed", because it "doesn't agree with people's requests" with the very detailed perception of the satiric material. Publishers and their cooperators prefer the serious style, because they believe it fits in thematic content dictated politically, expressed in the objectives and purposes of the newspaper.

It is noticed the placing of anectodes which is an effort of the newspaper to ease its "serious" character and giving it a notation of joke and joy that could attract the readers' attention, at the same time with its useful material. Nowadays anecdotes are nothing else than the continuation of the popular humorous stories with the only difference their shortening.

"Llaiko Vima" newspaper mainly requests discipline and ideological uniformity. This is the main characteristic of the articles of many journalists and correspodents. The detailed flow, the use of folk language, the ideological clarity, justice and popular humanism are some of the phylologic characteristics of the journalistic and literary style of pano Cuka who as the main representative of the minority writings of the time in this period, plays an important role in the newspaper. He had the skill to create lyrics and poems followed by a scientific responsibility and mentality. He is shown in the newspaper with a rich phylological work, scientific, literary and poetic. He translates from the Albanian literature many important works of the best known Albanian poets and writers like Ismail Kadare, Drago Siliqi, Nonda Bulka, Fatos Arapi, Ndoc Papleka, etc. His collaboration with the newspaper is inagurated on 10th August 1945 with the poem with title "Two societies" with his pseudonym Alqis Anthulis. The published poems in the newspaper later are part of its poetical summary.

As for the permanent and temporary co-operators of the newspaper we notice that the presence of women in the newspaper "LlaikoVima", in comparison with the presence of men is weak enough.

\section{Actuality Rubrics}

The last pages of each newspaper number follow with special interest actuality. This regular rubric, that is sheltered in different titles, makes its appearance since from the first number and continuous uninterruptedly till today.

"The pursuing of actuality" includes long and analytic comments, or short and formulated in concise way, news, events, , that have connection with the spiritual and cultural life, as well the social moving, economic and educational, or in specific of the town, where are the headquarters of the newspaper, or in general of all the Greek Minority territory- with small exceptions even of the other provincial towns out of the Ethnic Greek Minority territory, but even of the capital, when it was about themes that interested the Ethnic Greek Minority. The editors of the rubric select, in general, the autonomy.

After 1990 an important role in the rubric that we are examining, take place the presence of association and relations. Exist special references for their foundation, the aim of their function, hierarchy for the choosing of new leading groups, for the work they realise, or associated through dance evenings and meeting between their members, or spiritual, with the organisation of congresses and talkings, for the excursions that they organise in their native place knowing at the same time their spiritual treasure. In specific are published the competitionsthat are announced to write studies for different areas of the Ethnic Greek Minority. Moreover, their general use is characterised with special care as a beginning of cultural development of the Ethnic Greek Minority.

The newspaper never forgets to remind the honours, commendations, decorations and promotions, scientific and professional, of the chosen sons of the Ethnic Greek Minority, to comment with pride personalities that honour the spiritual Ethnic Greek Minority and refer to philological commemoration and mourning for different people of the Ethnic Greek Minority, who are famous in their country. The objective which it serves, is to show up the spiritual capacity of the zone, which is not behind for special personalities.

Problems of the economy of the zone, that bother all the professional and productive classes, the themes of technology, municipal work and of common benefit, are included in the pages of the newspaper, with the aim to become known generally the vivid activity in all the sectors of productive activity, except the spiritual one.

A topic that comes again in the pages of the newspaper is the sport's movement, the organization of sport's 
games, the care for the education, with the aim to be valued the spiritual and sport's capital.

An important place takes the interest for the touristic movement of the zone through the show of concrete proposals, such as the enlightenment and the decoration of historical places, the recognition of the cultural inheritance of mother land, the foundations of the museums etc. Also, the archeologic topic with interest to haste the archeological diggings and to enlight the hidden treasures, but even to find out other sides of the history, without living out their touristic exploitation.

The rubric follows with a special inerest the social activity, lectures and talkings that are organised closed or opened places, in different towns, with main reference the people of the Ethnic Greek Minority, and with themes, mainly of inerest for the Ethnic Greek Minority. This reformation sometimes is short and sometimes is enriched with comments for their content and success. The presence of the spiritual activities and cultural is realisedin the spectrum to make good examples even other provincial towns for the organization of same activities, but even to serve the Ethnic Greek Minority, for him to "stand on his feet" spiritualy.

A place at comments takes even the rise and the inaguaration of monuments and memorials to honour the outstanding people of activity and spirit. The newspaper's interest goes back regularly to the hero Lefter Talo etc.

In the commenting are included even the efforts for the creation of the cultural centers and places, the schools of music and libraries and even other buildings, that show culture. It is obvious the open demanding invitation, the encouragement for approach, the gathering and the registration of the folk material in a scientific style, the knowledge of circulation or the expected publications of books of the writers of the Ethnic Greek Minority.

In general the rubric that follows, that registers and comments the actuality in a first and fast look, it can be avoided in an indeferent way by the reader, but its about the rubric very interesting now and vivid, where welcomes every thought and viewpoint in connection with the problems that preoccupy the Ethnic Greek Minority. The future scholar, passing and numbering the specific pages, together with the variety of topics gathers valuable information, registers the spiritual scene and composes the spiritual travel of the Ethnic Greek Minority and in this way reaches in different conclusions. This panoramic view of the Ethnic Greek Minority life has the aim of serving the spiritual stay, to show up the intelect of the province. A precious rubric for the entering inte treasure of the events. Në përgjithësi rubrika që ndjek, që regjistron dhe komenton aktualitetin në një vështrim të parë dhe të nxituar, mund të anashkalohet në mënyrë indiferente nga lexuesi, por bëhet fjalë për rubrikën tashmë interesante dhe të gjallë, ku mirëpritet çdo mendim dhe pikëmapje në lidhje me problemet që preokupojnë Minoritetin Etnik Grek.

One of the journalistic interesting categories in the pages of the newspaper "Llaiko Vima" is the one always named under the term Chronicle. These kind of writings are presented as mixed texts, i.e they present values and qualities of pamphlet, humouristic sketch or reportage. Under the term chronicle are published all the time writings with topics taken from the capitalist life of foreign countries, usually of countries that in the political of the time were called revisionist and imperialist. They are no real cronicles in the journalistic style, but hibrid texts with the mentioned elements.

\section{References}

Corpus of newspaper "Llaiko Vima": (1945-2012).

Naçi, Kosta, (2005), "The History of the Literature of the Ethnic Greek Minority", Publishing House "Argjiro", Gjirokastër.

Swedish Helsinki Committee for Human Rights, (2005), "Minority Media", ISHM, Tirane.

Swedish Helsinki Committee for Human Rights, (2009), "Minority Media", ISHM, Tirane. 